\title{
Tahribatsız Yöntemler Kullanılarak Trafik Kaynaklı Yer Hareketi Etkisindeki Tarihi Yapıların Stokastik Dinamik Analizi
}

\author{
Stochastic Dynamic Analysis of Historical Structures subjected to Traffic-induced Ground \\ Motion using Non-destructive Methods
}

Kemal HACIEFENDIOĞLU*

Karadeniz Teknik Üniversitesi, Mühendislik Fakültesi, İnşaat Mühendisliği Bölümü, 61080, Trabzon

• Geliş tarihi / Received: 17.05.2019 • Düzeltilerek geliş tarihi / Received in revised form: 01.01.2020 • Kabul tarihi / Accepted: 07.01.2020

\begin{abstract}
Öz
$\mathrm{Bu}$ çalı̧̧mada, trafik geçişleri sebebiyle zeminde meydana gelen yatay mikro titreşim yer hareketi etkisi altındaki tarihi bir yığma yapının stokastik dinamik analizlerinin gerçekleştirilmesi amaçlanmaktadır. Bu amaçla, yerinde tahribatsız yöntemler uygulanarak yapıda kullanılan malzeme özelliklileri tespit edilmeye çalışılmıştır. Yerinde tahribatsız yöntem olarak ultrasonik hız testi uygulanmış ve taş duvar, tuğla kemer ve taş kolonlar için belirlenen noktalardan ölçümler alınmıştır. Yerinde yapılan ölçümler ile elde edilen veriler kullanılarak yapı analizlerinde kullanılan taş kolon, taş duvar ve tuğla kemer için malzeme özellikleri tespit edilmiştir. Bu çalışmada, yapının trafik etkisi altındaki stokastik dinamik analizlerinin elde edilmesi için trafik kaynaklı yer hareketi modeli elde edilmiștir. Stokastik dinamik analizler yapının hasarsız (çatlaksız) ve hasarlı (çatlaklı) halleri için gerçekleştirilmiş ve sonuçlar karşılaştırılmıştır.
\end{abstract}

Anahtar kelimeler: Çatlak, Stokastik Dinamik Analiz, Tahribatsız Test, Tarihi Yığma Yapı, Ultasonik Hız Testi

\begin{abstract}
In this study, it is aimed to perform stochastic dynamic analysis of a historical masonry structure subjected to horizontal micro vibration ground motion occurring on the ground due to traffic transitions. For this purpose, nondestructive methods were applied to determine the material properties used in the historic building. Ultrasonic velocity test was applied as a non-destructive method and measurements were taken from the points determined for stone walls, brick arches and stone columns. The material properties of the stone columns, stone walls and brick arches used in the structural analyzes were determined by using the data obtained from the on-site measurements. In this study, to obtain the stochastic dynamic analysis of the structure under the influence of traffic, a traffic induced ground motion model was obtained. The stochastic dynamic analysis was performed for undamaged (non-cracked) and damaged (cracked) structure and the results were compared.
\end{abstract}

Keywords: Crack, Stochastic Dynamic Analysis, Non-destructive Testing, Historical Masonry Structure, Ultrasonic Speed Test

*Kemal HACIEFENDİĞLU, kemalhaciefendioglu@ktu.edu.tr, Tel: (0462) 377 2669, orcid.org/ 0000-0002-5791-8053 


\section{Giriş}

Tarihi yapıların bir ülkenin tarihi mirası olması sebebiyle deprem, yerel titreşim, trafik, rüzgâr v.b. gibi dış yükler etkisi altındaki dinamik davranışlarının tespit edilmesi oldukça önemlidir. $\mathrm{Bu}$ yapıların dış yükler etkisi altındaki davranışlarının tahmin edilmesi amacıyla öncelikle malzeme özelliklerinin tespit edilmesi gerekmektedir. Yapıda malzeme özelliklerinin tespiti, mümkünse tahribatsız yöntemlerle, bu mümkün olmazsa az tahribatlı yöntemlerle, bu da mümkün değilse tahribatlı deneyler yapılarak belirlenir. Yap1 elemanları ve malzemelerinde yüzey sıcaklığı ve nemi, yüzey sertliği ve ultrases (hız) ölçümü gibi işlemlerde magnometri, infrared/termografi, georadar/radar tarama gibi tahribatsız deneyler uygulanmaktadır.

Tarihi yapıların yıllar boyu dış yükler etkisinde kalması sebebiyle, yapılan ölçüm ve analizler sonucunda genellikle onarım ve güçlendirme gereksinimi ortaya çıkmaktadır. Tarihi yığma yapıların tahribatsız ya da tahribatlı yöntemlerle incelenmesi amaciyla geçmişten günümüze kadar çok sayıda çalışmalar yapılmıştır. Betonarme yapılardaki betonun ya da tarihi yapılarda yap1 malzemesi olarak kullanılan taşların mekanik özelliklerini belirlemek için, Ultrasonik testler (Moropoulou vd., 2003; Uyanık vd., 2011, 2012, 2013, 2019; Faella vd., 2012; Başaran vd., 2016; Vasanelli vd., 2016; Öziçer ve Uyanık, 2017, Sabbağ ve Uyanık, 2017, Zielińska ve Rucka, 2018; Mesquita vd., 2018), Schmidt testi (Başaran vd., 2016; Vasanelli vd., 2016; Öziçer and Uyanık, 2017), tek eksenli basınç ya da brazilian testleri (Başaran vd., 2016; Öziçer ve Uyanık, 2017; Sabbağ ve Uyanık, 2017; Uyanık vd., 2019) birçok araştırmacı tarafindan kullanılmıştır. Ayrıca yapı malzemeleri içerisindeki kırık, boşluk ya da donatı gibi farklılıkları belirleyebilmek için yap1 radar testleri (Faella vd., 2012) kullanılmaktadır. Bunlara ek olarak yap1 malzemesi içerisindeki nemliliği ya da korozyon durumu için elektrik özdirenç (Sabbağ ve Uyanık, 2018) yöntemi etkin bir biçimde uygulanmaktadır. Ultrasonik tomografi yönteminin tuğla kolonların iç yapısının rekonstrüksiyonunda etkili bir teknik olduğu görülmüştür. Sunulan yaklaşımda özellikle güçlendirilmiş uygulamaların teşhisinde ve donatı malzemelerinin tuğla yapılara uygunluğunun değerlendirilmesinde faydalı olduğu kanıtlanmıştır.

Trafik kaynaklı yer hareketleri sebebiyle oluşan yer titreşimleri mikro seviyelerde olmasına karşın bu yüklerin sürekli tekrarlanan ve yüksek frekanslı bir yük olması sebebiyle tarihi yapılarda risk oluşturmaktadır (Kliukas vd., 2008). Tarihi yapıların yapımında kullanılan malzemelerin çekmeye karşı mukavemetleri çok yüksek olmaması sebebiyle yapılarda bu titreşimler altında zamanla harç sökülmesi, tuğla ya da blok ayrılmaları meydana gelebilmektedir. $\mathrm{Bu}$ gibi sebeplerle dayanımı zamanla azalabilen tarihi yapilar risk altında bulunmaktadır (Erkal, 2017). Tarihi yapıların trafik kaynaklı mikro-titreşim şeklindeki yer hareketi sebebiyle oluşan dinamik davranışları ile ilgili bazı çalışmalar gerçekleştirilmiştir (Crispino ve D'Apuzzo, 2001; Erkal vd., 2010; Bongiovanni vd., 2011; Ma vd., 2011; Erkal, 2017, 2018). Mikro-titreşim hissedilme eşiği genellikle $0.14-15 \mathrm{~mm} / \mathrm{s}$ tane hızındadır. Bu çalışmaların amacı, tarihi yapının yakınında oluşan trafik kaynaklı titreşimlerin yapıya hasar verici nitelikte olup olmadığının araştırılması ve yapının korunmasına ihtiyaç duyulup duyulmadığıdır.

$\mathrm{Bu}$ çalışmada, trafik geçişleri sebebiyle zeminde meydana gelen yatay mikro titreşim yer hareketi etkisi altındaki tarihi yığma bir yapının (Samsunİlkadım-Taşhan) stokastik dinamik analizlerinin gerçekleştirilmesi amacıyla yerinde tahribatsız yöntemler uygulanarak yapıda kullanılan malzeme özellikleri tespit edilmeye çalışılmıştır. Yerinde tahribatsız yöntem olarak ultrasonik hiz testi uygulanmış ve taş duvar, tuğla kemer ve taş kolonlar için belirlenen noktalardan ölçümler alınmıştır. Yapının trafik etkisi altındaki stokastik dinamik analizlerinin elde edilmesi için trafik kaynaklı yer hareketi modeli elde edilmiştir. Stokastik dinamik analizler yapının hasarsız (çatlaksız) ve hasarlı (çatlaklı) halleri için gerçekleştirilmiş ve sonuçlar karşılaştırılmıştır.

\section{Yapı Bilgisi}

\subsection{Yapının Mevcut Durumu}

1508 Yılında yapılan Taşhan kare planlı, iki katlı, avlulu olan Osmanlı dönemi şehir hanları plan özelliklerindedir. Dönem özelliklerini taşıyan, altta ahır ve servis mekânları, üstte yolcuların konaklaması için mekanların planlandığı iki katlı han grubundadır. Yapının zemin katında ahır ve depo mekânları oluşturulmuştur. Üst katında misafirler için planlanmış 24 oda vardır. Han yapısına cepheden kare planda ileri taşan yapı kütlesinin ortasındaki kemerli bir kapidan girilmektedir. Kapıdan bir koridorla avluya çıkılmaktadır. Hanın avlusu kare formludur ve her bir yönde üçer kemer boşluğu olan revak yapısıyla çevrilidir. Revak arkasında bir yönde ahır bölümü, 
diğer yönde küçük hücrelerle bölünmüş depo yer almaktadır. Birçok benzeri şehir hanında olduğu gibi Taşhan'da da merdiven tek kollu olarak revak içinde planlanmıştır. Hanın üst katı da dört yönde üçer kemerli açıklıklı revak ile çevrilmiştir. Revakların kemerleri tam kemere yakın sivri kemerlidir. Odalar revak arkasında yer almaktadır. Üst katın köşelere denk gelen dört odasına pahlandırılarak yapılmış köşelerdeki kapılardan girilir. Handaki üst kat odalarının tümünde ocak vardır (bacalarıyla birlikte). Revak bölümüne açılan oda cephelerinde pencere bulunmaz. Kuzey-Batı köşesindeki yalnız tepe pencereleri bulunan oda dışında bütün odalarda pencere ve üstlerinde tepe penceresi vardır (Şekil 1-3).

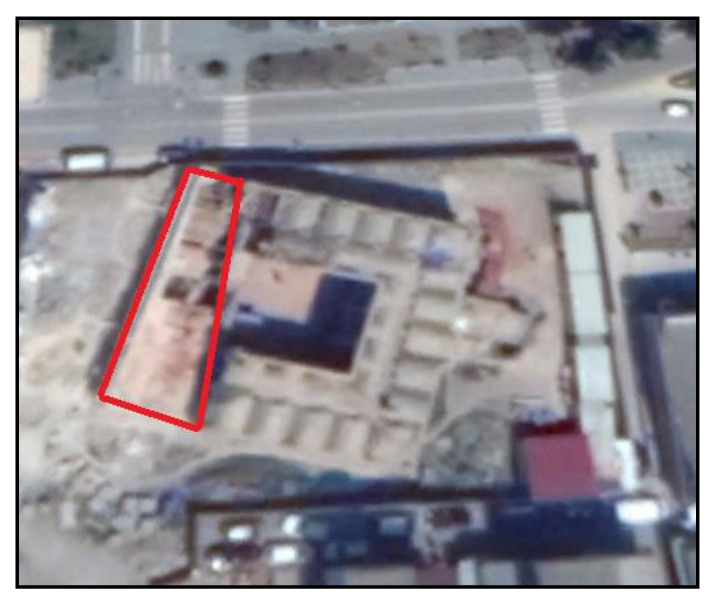

(a)

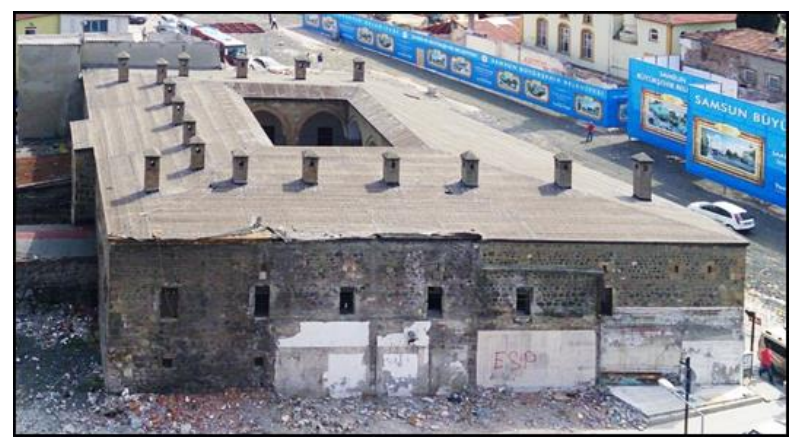

(b)

Şekil 1. (a) Taşhan'ın yıkılan ve tamamlanacak k1sm1, (b) batı cephesi

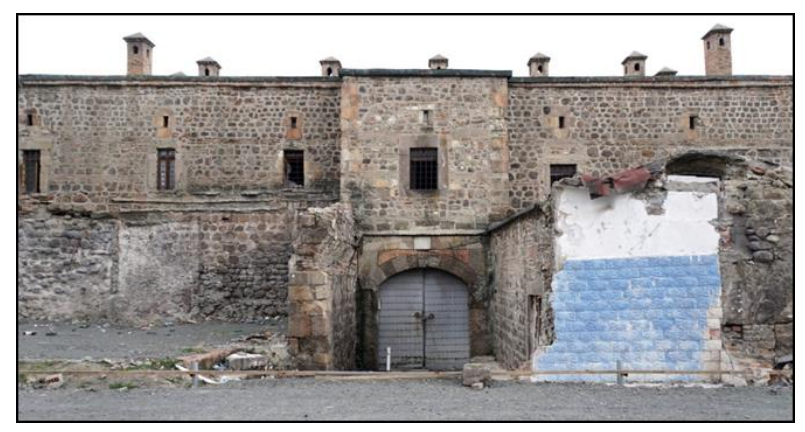

Şekil 2. Samsun Taşhan doğu (giriş) cephesi

\subsection{Ultrasonik Ölçümler}

Ultrasonik hız deneyleri yapı üzerinde (taş duvar, taş kolon, tuğla kemer) ve yapıda kullanılan numuneler üzerinde laboratuvar ortamında yapılmıştır. $\mathrm{Bu}$ deneyde yüksek frekanslı ses dalgas1 üreten Ultrasonik cihazdan yararlanılmıştır. Ölçümler aynı yüzeyden dolaylı olarak yapılmıştır. Malzeme boşluklu, yoğunluğu düşük ve/veya bünyesinde çatlaklar var ise ses geçiş hızı düşüktür. Ses geçiş hızı ile malzemelerin homojenliği karşılaştırılabilir, yüzey sertliği ve karot numunelerinin deney sonuçları ile birlikte değerlendirilerek, dayanımı tahmin edilir (Ercan, 2003; Uyanik vd., 2012, 2013).

Yığma duvarların malzeme özelliklerini elde etmek için en çok uygulanan tahribatsız test yöntemleri arasında sonik test yer almaktadır. Sonik testler, malzeme özelliklerinin belirlenmesi ve yapısal elemandaki boşluklar, çatlaklar veya diğer kusurlar gibi iç süreksizliklerin belirlenmesi gibi farklı amaçlar için kullanılmaktadır. Temel olarak, sonik testte, malzeme mukavemetinin veya iç süreksizliğin tanımlanması, baskın ultrasonik dalganın duvarda hareket süresiyle ilgilidir. Sonic testinde verici ve alıcı kullanılır ve hesaplar verici ve alıcı arasındaki mesafeye ilişkin formüller kullanılarak gerçekleştirilir. Yığma yapıların duvar kalınlıklarının büyük olması karşılıklı duvar boyunca dalga yayilımin elde edilememesine sebep olmaktadır. $\mathrm{Bu}$ sebeple, bu çalışmada yüzeysel dalga yayılımları dikkate alınarak çalışmalar gerçekleştirilmiştir (Şekil 3). Yapıda yerinde yapılan ultrasonik testler sonucu her bir kat için taş duvar, taş kolon ve tuğla kemerlerde elde edilen ultrasonik hız değerleri Tablo 1'de gösterilmiştir. Tabloda görüldüğü üzere taş duvar, tuğla kemer ve taş kolonlar için her kattan ayrı ayrı ölçümler alınmıştır. Elde edilen tüm veriler kullanılarak malzemelerin dinamik elastisite modülleri hesaplanmıştır. Yapının sonlu elemanlar yöntemi ile sismik analizinin daha doğru bir şekilde gerçekleştirilmesi amacıyla ultrasonik ölçümlerin ortalama değerleri kullanılmıştır. Samsun Taşhan sonlu elemanlar modelinde kabul edilen malzeme özellikleri Tablo 2'de özetlenmiştir. Tablo 2'deki Poisson Oranları literatürde elde edilen ortalama değerlerdir.

Tablo 2'de, $V_{R}, V_{P}$ ve $V_{S}$, sirasiyla Rayleigh, Birincil ve İkincil dalgalardır. Pozitif Poisson oranına ( $v>0$ ) sahip doğrusal elastik malzemeler için, Rayleigh dalga hızı, Birincil ve İkincil dalgalar arasındaki ilişki Denklem (1) (Richart vd., 1970; Freund, 1998) ve Denklem (2) (Uyanık, 2012) ile verilebilir. 




Şekil 3. Ultrasonik test yüzeysel ölçümü sistematiği

$\frac{V_{R}}{V_{S}}=\frac{0.862+1.14 v}{1+v}$
$\frac{V_{P}}{V_{S}}=\left\{\frac{2(1-v)}{1-2 v}\right\}^{0.5}$

Ayrıca, kayma dalga hızı kullanılarak Denklem (3) ile dinamik elastisite modülleri hesaplanabilir.

$E_{d}=2 \rho(1+v) V_{S}^{2}$

Burada, $\rho\left(\mathrm{gr} / \mathrm{cm}^{3}\right)$ yoğunluktur.

Bunlara ilave olarak ölçülen ve hesaplanan dalga hızlarına bağlı olarak yoğunluklar Denklem (4) (Gardner vd., 1974) ile hesaplanabilir.

$\rho=0.31 V_{P}^{0.25}$

Yukarıda belirtilen formüller kullanılarak öncelikle aynı bölgeden alınan ultrasonik ölçüm, $\mathrm{V}_{\mathrm{r}}$, değerlerinin ortalamaları elde edilmiş ve bu değerlere bağlı olarak $\mathrm{V}_{\mathrm{s}}, \mathrm{V}_{\mathrm{p}}, \rho$ ve Elastisite Modülü değerleri hesaplanmıştır. Bu değerlerin hesaplanmasında Poisson oranı sabit alınmıştır.

Tablo 1. Yapıda taş duvar, taş kolon ve tuğla kemer için ultrasonik ölçüm, yoğunluk ve Elastisite Modülü değerleri

\begin{tabular}{|c|c|c|c|c|c|c|c|c|c|}
\hline \multirow{2}{*}{ 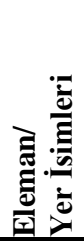 } & \multirow[b]{2}{*}{$\begin{array}{l}\text { Yapı Elemanı ve } \\
\text { Açıklama } \\
\text { Duvar Numaraları }\end{array}$} & \multicolumn{3}{|c|}{ Ultrasonik Ölçümler } & \multicolumn{5}{|c|}{ Hesaplamalar } \\
\hline & & \multicolumn{3}{|c|}{$\mathbf{V}_{\mathbf{r}}(\mathbf{m} / \mathbf{s})$} & $\begin{array}{l}\text { Ortalama } \\
\left(\mathbf{V}_{\mathbf{r}}\right)\end{array}$ & $\begin{array}{l}\mathbf{V}_{\mathrm{s}}(\mathbf{m} / \mathbf{s}) \\
\text { (Denk.1) }\end{array}$ & $\begin{array}{l}\mathrm{V}_{\mathrm{p}}(\mathrm{m} / \mathrm{s}) \\
(\text { Denk.2) }\end{array}$ & $\begin{array}{l}\rho \\
\left(\mathrm{gr} / \mathrm{cm}^{3}\right)\end{array}$ & $\begin{array}{l}\text { Elastisite } \\
\text { Modülü } \\
\text { (MPa) }\end{array}$ \\
\hline \multirow{11}{*}{ 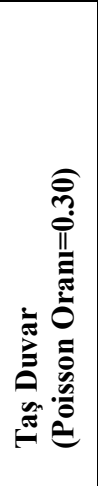 } & ZA 1-2 DV & 2000 & 1290 & 600 & 1297 & 1398 & 2615 & 2.217 & 1026.06 \\
\hline & ZC 1-2 DV & 2460 & 2240 & 1880 & 2193 & 2364 & 4423 & 2.528 & 2935.80 \\
\hline & ZD 1-2 DV & 1920 & - & - & 1920 & 2070 & 3872 & 2.445 & 2249.67 \\
\hline & ZBC 8 DV & 2010 & - & & 2010 & 2167 & 4053 & 2.474 & 2465.52 \\
\hline & 18 D-E TAŞ DUVAR & 1110 & - & - & 1110 & 1197 & 2238 & 2.132 & 751.90 \\
\hline & 1A 5-6 TAŞ DUVAR & 1900 & 1100 & - & 1500 & 1617 & 3025 & 2.299 & 1373.09 \\
\hline & 1D 7-8 TAŞ DUVAR & 990 & - & - & 990 & 1067 & 1996 & 2.072 & 598.12 \\
\hline & 1A 5-6 TAŞ DUVAR & 1900 & 1100 & - & 1500 & 1617 & 3025 & 2.299 & 1373.09 \\
\hline & $1 \mathrm{~F} 1-2 \mathrm{DV}$ & 1850 & 2220 & - & 2035 & 2194 & 4104 & 2.481 & 2527.24 \\
\hline & \multicolumn{6}{|c|}{ Taş duvar ortalama= } & & 2.328 & 1700.05 \\
\hline & E2 KOLON & 1360 & - & - & 837 & 1079 & 1727 & 2.169 & 1069.15 \\
\hline \multirow{6}{*}{ 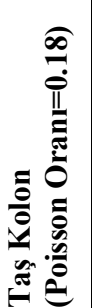 } & E3 KOLON & 1820 & 1640 & 1420 & 1085 & 1791 & 2867 & 2.268 & 1529.53 \\
\hline & D6 KOLON & 1210 & 1120 & 1210 & 1165 & 1299 & 2080 & 2.094 & 804.87 \\
\hline & 1 E3 TAŞ KOLON & 1530 & 1510 & 1170 & 1180 & 1545 & 2474 & 2.186 & 1138.37 \\
\hline & 1 C4 TAŞ KOLON & 1120 & 1740 & - & 1080 & 1575 & 2521 & 2.197 & 1182.05 \\
\hline & 1 E6 TAŞ KOLON & 2000 & 1050 & - & 837 & 1679 & 2688 & 2.232 & 1344.32 \\
\hline & \multicolumn{6}{|c|}{ Taş kolon ortalama= } & & 2.191 & 1178.05 \\
\hline \multirow{6}{*}{ 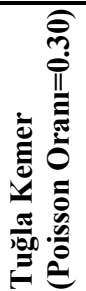 } & ZC6 TUĞLA KEMER & 910 & 440 & 1160 & 1360 & 902 & 1826 & 2.027 & 411.60 \\
\hline & ZD6 TUĞLA KEMER & 1230 & 940 & - & 1627 & 1170 & 2368 & 2.163 & 692.20 \\
\hline & ZF6 TUĞLA KEMER & 1100 & - & 1230 & 1180 & 1038 & 2103 & 2.201 & 798.04 \\
\hline & 1 C4 TUĞLA KEMER & 1180 & - & - & 1403 & 1272 & 2576 & 2.208 & 818.72 \\
\hline & 1 C5 TAŞ KEMER & 1080 & - & - & 1430 & 943 & 1910 & 2.160 & 685.83 \\
\hline & \multicolumn{6}{|c|}{ Tuğla kemer ortalama= } & & 2.152 & 681.28 \\
\hline
\end{tabular}


Tablo 2. Samsun Taşhan sonlu elemanlar modeli için malzeme özellikleri

\begin{tabular}{|l|c|c|c|}
\hline Eleman tipi & Elastisite Modülü (MPa) & Yoğunluk (gr/cm $\mathbf{3}^{\mathbf{}}$ ) & Poisson Oranı \\
\hline Taş duvarlar (harç ile birlikte) & 1700.05 & 2.328 & 0.30 \\
\hline Taş kolonlar (harç ile birlikte) & 1178.05 & 2.191 & 0.18 \\
\hline Kemerler ve tonozlar & 681.28 & 2.152 & 0.30 \\
\hline
\end{tabular}

\section{Formülasyon}

\subsection{Stokastik Dinamik Analiz}

$N$ serbestlik dereceli bir yap1 sisteminin sönüm içeren dinamik hareket denklemi aşağıdaki gibi yazılabilir.

$$
M \ddot{u}(t)+C \dot{u}(t)+K u(t)=-M \delta \ddot{u}_{g}(t)
$$

Bu ifadede $M, C, K$ sirasıyla kütle, sönüm, rijitlik matrislerini, $\ddot{u}(t), \dot{u}(t), u(t)$ ivme, h1z ve yerdeğiştirme vektörlerini, $\delta$ deprem doğrultu vektörünü, $\ddot{u}_{g}(t)$ yer ivmesini göstermektedir.

Yap1 sistemlerinin stokastik dinamik analiz formülasyonu y1llardan beri çok iyi bilindiğinden bu çalışmada sadece kısaltılmış formülasyon verilecektir. Ayrıntılı stokastik dinamik analiz formülasyonu bir çok kaynakta (Lin, 1967; Yang, 1986; Clough ve Penzien, 1993; Manolis ve Koliopoulos, 2001) verilmektedir.

Güç spektral yoğunluk fonksiyonu ve otokorelasyon fonksiyonu stokastik analiz için temel ifadelerdir. Bir sisteme etkiyen deprem hareketinin güç spektral yoğunluk fonksiyonu veya otokorelasyon fonksiyonu bilinirse, yap1 davranışını tanımlayan stokastik parametreler kolayca belirlenebilir. Davranışın karşıt güç spektral yoğunluk fonksiyonu, $S_{\mathrm{ij}}(\omega)$, sistem hareket denklemi, Denklem (6), kullanılarak gerekli işlemler yapıldıktan sonra,

$$
S_{\mathrm{ij}}(\omega)=S_{\ddot{v}_{g}}(\omega) \sum_{r=1}^{N} \sum_{s=1}^{N} \Psi_{\mathrm{ir}} \Psi_{\mathrm{js}} H_{\mathrm{ir}}(\omega) H_{\mathrm{js}}^{*}(\omega)
$$

şeklinde elde edilir. Burada $S_{\ddot{v}_{g}}(\omega)$, yer ivmesinin güç spektral yoğunluk fonksiyonunu, $H(\omega)$, frekans davranış fonksiyonunu, * kompleks eşleniği, $N$, davranışa katkısı olan mod sayısını, $\psi_{j r}$ ise r'nci modun $u_{j}(t)$ yerdeğiştirmesine katkısını göstermektedir.

Davranışın güç spektral yoğunluk fonksiyonu ve frekans terimleri ile ifade edilen spektral momentler, $\lambda_{m, i j}$,

$$
\lambda_{\mathrm{m}, \mathrm{ij}}=2 \int_{0}^{\infty} \omega^{m} S_{\mathrm{ij}}(\omega) d \omega \quad, m=0,1,2
$$

bağıntısıyla hesaplanmaktadır. Burada $m=0,1,2$ sırasıyla sifirınc1, birinci, ikinci spektral momenti göstermektedir.

Stokastik dinamik analizde kullanılan istatistiksel parametrelerin en önemlilerinden biri de ortalama maksimum değerdir. Ortalama maksimum değer $\mu$, tüm maksimum değerlerin ortalaması olarak tanımlanır ve genelde maksimum büyüklük faktörüne ve davranışın karesel ortalamasının kareköküne bağlı olarak aşağıdaki gibi ifade edilir.

$\mu=p \sqrt{\lambda_{0}}$

Burada, $p$ ve $\lambda_{0}$ sirasiyla deprem ivmesinin maksimum büyüklük faktörünü ve sıfirınc1 spektral momenti göstermektedir.

\subsection{Trafik Kaynaklı Yer Hareketi}

$\mathrm{Bu}$ çalışma ile, trafik geçişleri sebebiyle zeminde meydana gelen yatay mikro titreşimlerin tarihi Samsun Taşhan yapısı üzerindeki etkilerini incelemeyi hedeflenmiştir. Mevcut durumdaki tarihi yapının çok yakınından geçen hafif raylı yolcu taşıma aracı ve araç trafiği sebebiyle meydana gelen mikro titreşimlerin yapı üzerinde meydana getirdiği dinamik davranışları elde etmek için trafik kaynaklı ortalama bir maksimum ivme değerine sahip yer hareketi güç spektral yoğunluk fonksiyonu oluşturulmuştur. Yang ve Agrawal (2001) trafik kaynaklı yer hareketini modellemek için stasyoner olmayan rastgele işlem modelini kullanmışlardır. Trafik kaynaklı yatay yer hareketi için stasyoner ivme zaman alanı örneği geliştirilmiş Kanai (1957)-Tajimi (1960) güç spektral yoğunluk fonksiyonu kullanılarak (GSYF) ilk kez elde edilmiştir.

$S_{\ddot{v}_{g}}(\omega)=\left(S_{0}\right)^{2} \frac{f_{g}^{4}+4 \xi_{g}^{2} f_{g}^{2} f^{2}}{\left(f_{g}^{2}-f^{2}\right)^{2}+4 \xi_{g}^{2} f_{g}^{2} f^{2}} \frac{f^{4}}{\left(f_{f}^{2}-f^{2}\right)^{2}+4 \xi_{f}^{2} f_{f}^{2} f^{2}}$

Burada $f_{g}$ ve $\xi_{g}$ sirasiyla zemine ait doğal frekans1 ve sönüm oranını, $\mathrm{S}_{0}$ seçilen trafik kaynaklı yer hareketinin ivme genlik değerini göstermektedir. Bu çalışmada Yang ve Agrawal tarafindan önerilen $f_{g}=10.8 \mathrm{~Hz}, \xi_{g}=0.75$, 
$f_{f}=38 \mathrm{~Hz}$ ve $\xi_{f}=0.35$ filtre parametre değerleri kullanılmaktadır. Trafik toplam geçiş süresi 15 sn olarak dikkate alınmıştır. Yer hareketi yoğunluğu $\mathrm{S}_{0}, 3.0 \mathrm{~cm} / \mathrm{sn}^{2}$ maksimum yer hareketi ivmesine karşı1lı değeri olarak seçilmiştir. Trafik kaynaklı yatay yer hareketi güç spektral yoğunluk fonksiyonu Şekil 4'te gösterilmektedir.

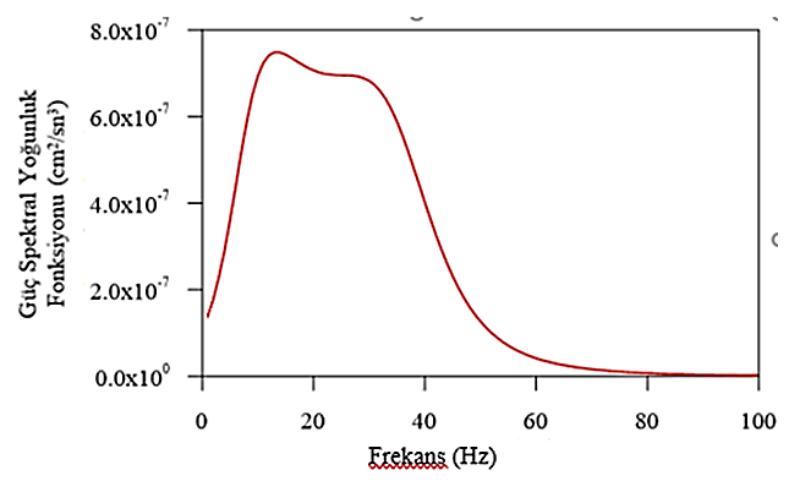

Şekil 4. Trafik kaynaklı yatay yer hareketi güç spektral yoğunluk fonksiyonu

\section{Uygulama}

Trafik kaynaklı yer hareketi sebebiyle tarihi yapıda meydana gelen mikrodinamik davranışların tahmin edilmesi amacıyla ANSYS programı (2013) kullanılmıştır. Analizler, yapının çatlaklı ve çatlaksız halleri için gerçekleştirilmiş olup sonuçlar karşılaştırılmıştır. Trafik kaynaklı yatay yer titreşim geçiş işlemi Şekil 5'de gösterilmiştir. Analizlerde trafik kaynaklı yer hareketinin yapıya y ekseni doğrultusunda etkidiği varsayılmıştır.



Şekil 5. Trafik kaynaklı yatay yer titreşim geçiş işlemi

Son y1llarda bilgisayar teknolojisindeki gelişmelere paralel olarak yapısal analiz programlarının kapasitelerinin artması ve grafik veri hazırlama kolaylıkları, özellikle karmaşı geometriye sahip tarihi binaların yapısal analizlerine olan talebi artırmıştır. Grafik ara yüz programlarıyla hazırlanan veriler analitik modelleme kurallarına dikkat edilmeden hazırlanırsa çok önemli hatalara yol açabilir. Bu nedenle, tarihi binaların sonlu elemanlar yöntemiyle yapılan hesaplarında modelleme aşaması çok önemlidir. Samsun Taşhan yapısı onarım ve güçlendirme yapılmadan önce Şekil 6'te görüldüğü üzere tonozlarda ve duvarlarda ağır hasarlı çatlaklara sahiptir. Yap1 modellenirken yapıda oluşmuş olan çatlakların mutlaka dikkate alınması gerektiği ve analizlerin buna göre gerçekleştirilmesi gerektiği vurgulanmak zorundadır. Şekil 7'de yapının geometrik özellikleri, taş duvar kalınlıkları, taş kolon boyutları, kemer açıklık ve kat yükseklikleri verilmiştir. Verilen boyutlara göre modellenen yapıda meydana gelen çatlak bölgelerinde bulunan duvarların her iki yanı ANSYS programında sürtünmeli olarak tasarlanmıştır (Şekil 8).

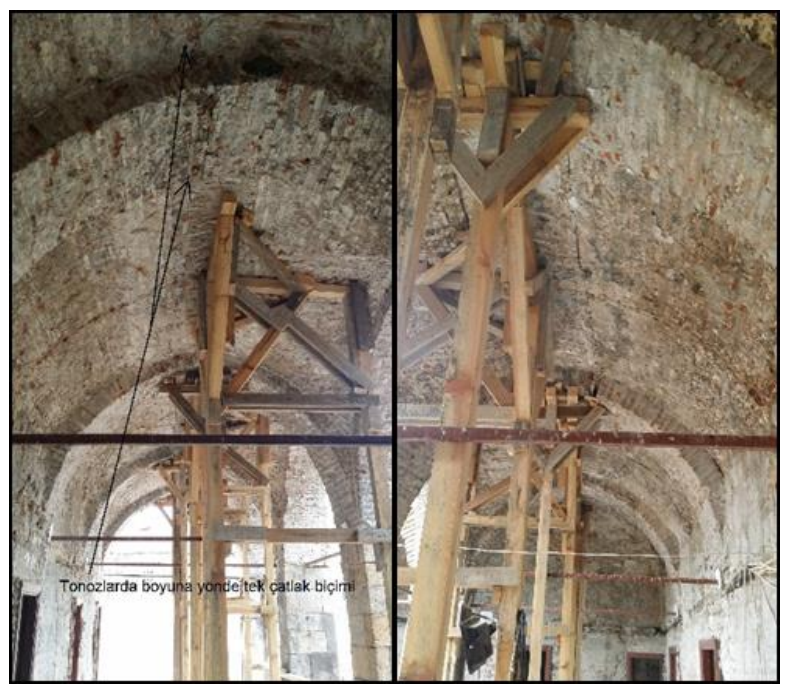

Şekil 6. Tonozlarda boyuna yönlü tek çatlak biçimi (anahtar solunda veya sağında)

$\mathrm{Bu}$ analizde yapının kendi ağırlığında ve her iki yönde deprem etkisi olması halinde sonuçlar elde edilmiş ve karşılaştırılmıştır. Bu çalışmada iki analiz gerçekleştirilmiştir. Birinci analizde yapının mevcut durumunda eklenecek kısmın var olduğu düşünülerek ve çatlakların mevcut olduğu durum için sonuçlar elde edilmiştir. İkinci analizde ise yapının onarım ve güçlendirme işlemleri yapıldıktan sonraki durumu dikkate alınmış ve sonuçlar elde edilmiştir (Bina tamamlanmış ve çatlaksız). 


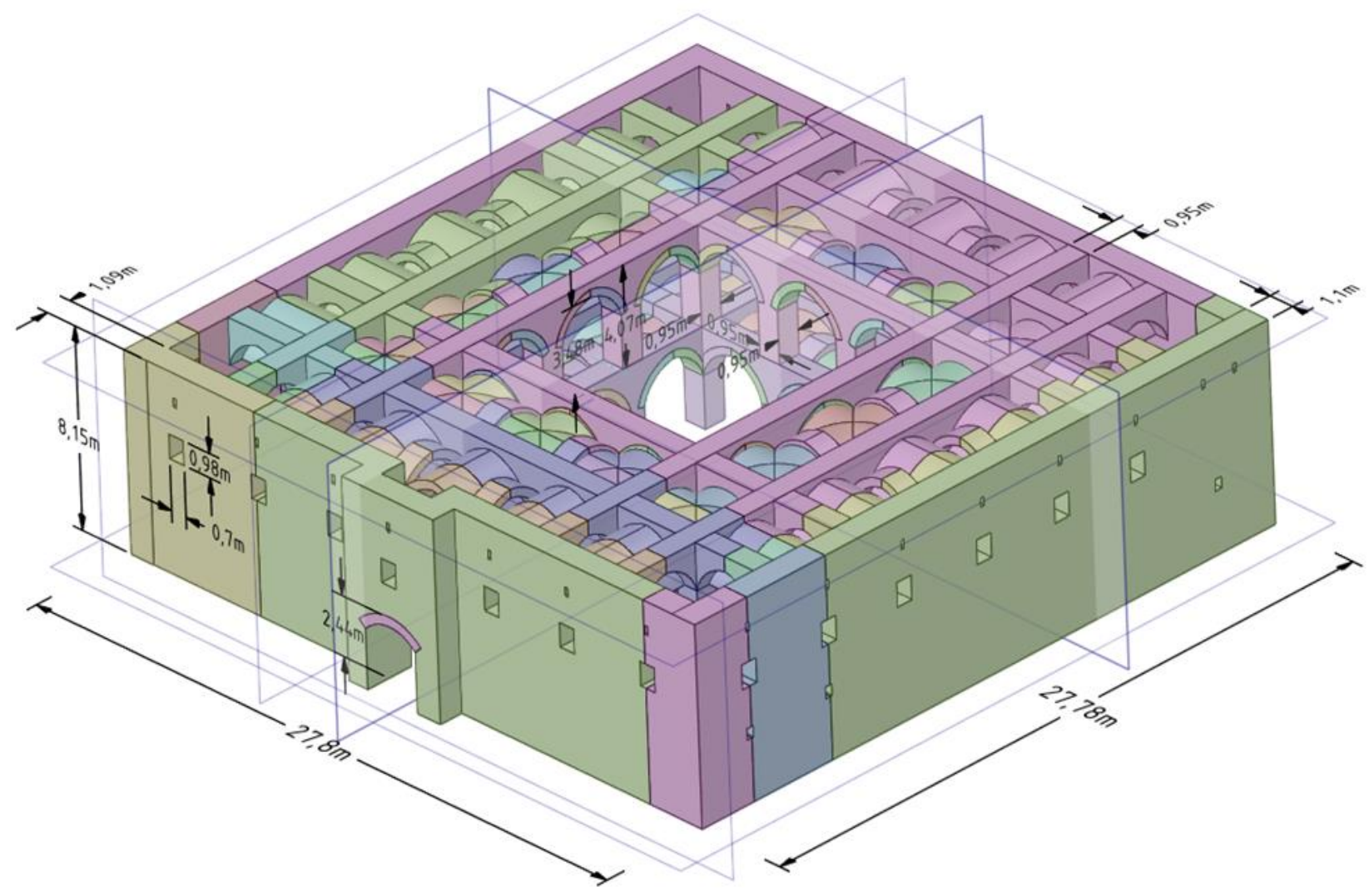

Şekil 7. Samsun Tarihi Taşhan'ın geometrik ölçütleri

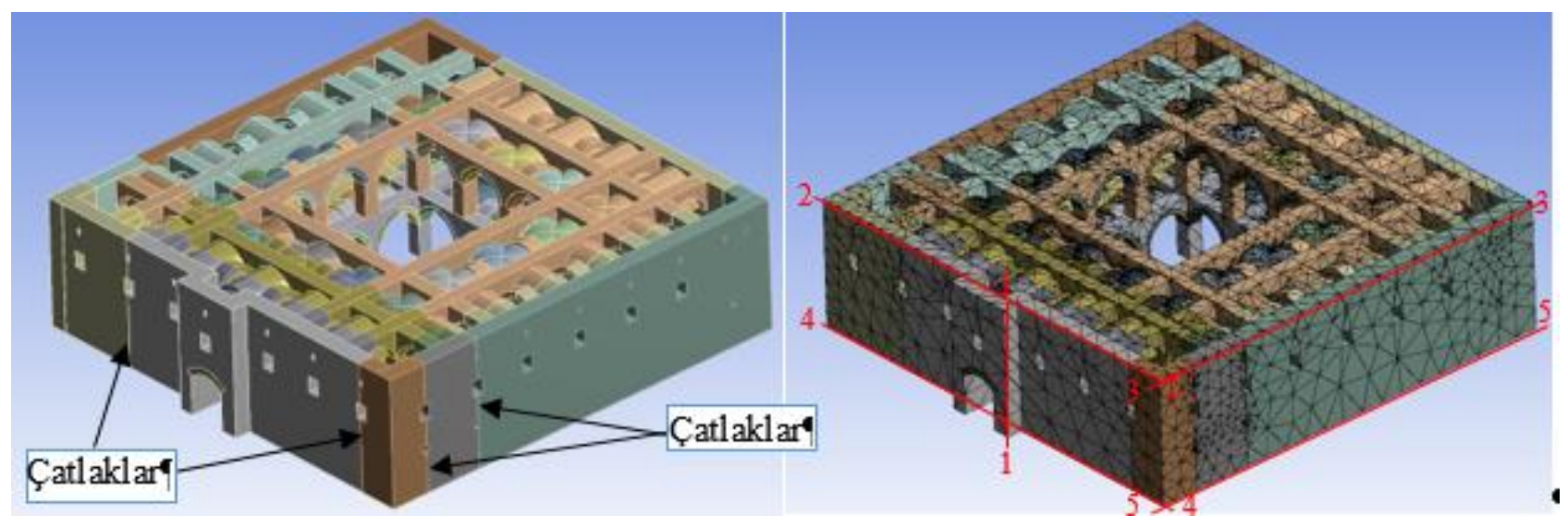

Şekil 8. Samsun Tarihi Taşhan'ın katı ve sonlu elemanlar modeli

Şekil 8'de gösterilen Samsun tarihi Taşhan'ın katı modeli Solidworks program1, sonlu elemanlar modeli ise ANSYS (2013) programının modelleme özellikleri ve kurallarına göre hazırlanmıştır. Yapının matematiksel modelinin oluşturulması için gerekli olan bütün geometrik boyutlar ve ölçüler, daha önce hazırlanmış olan rölöveler kullanılarak elde edilmiştir. Modelleme ve hesap parametreleri aşağıda maddeler halinde sunulduğu gibidir:
- Yapının tüm elemanları "Solid" elemanları ile modellenmiştir.

- Hesaplar için hazırlanan matematiksel model 130739 düğüm noktasi ve 59009 Solid eleman kullanılarak oluşturulmuştur.

- Taş yığma yapi elemanlarının, harç ile birlikte tek bir malzeme özelliği gösterdiği varsayılmıştır. $\mathrm{Bu}$ varsayımı kabul edilebilir yapacak Elastisite Modülü ve birim ağırlık kabulleri yapılmıştır. Buna bağlı olarak taş+tuğla duvarlar, taş kolonlar, kemer ve tonozlar ayrı ayrı modellenmiştir. 


\section{Analizler}

$\mathrm{Bu}$ çalışmada, trafik kaynaklı rastgele yer hareketi etkisindeki tarihi Taşhan yapısının hasarsız ve hasarlı durumları dikkate alınarak stokastik dinamik analizleri gerçekleştirilmiştir. Şekil 8'de gösterilen kesitler için ortalama maksimum yerdeğiştirme (y doğrultusunda) ve eşdeğer gerilme değerleri elde edilmiş ve hasarsız ve hasarlı durumlar için karşılaştırılmıştır.

Şekil 9'da yapının hasarsız ve hasarsız durumları için yerdeğiştirme değerleri gösterilmektedir. Şekilden de görüleceği üzere, hasarsız durumda maksimum yerdeğiştirmeler yapının arka tarafina doğru tepe noktasında meydana gelirken hasarlı durumda çatlak bölgelerine yakın kısımlarda, özellikle her iki yönde çatlak olan kısımlarda oluşmaktadır. Yapının yerdeğiștirme eğilimi hasarsız durumda $\mathrm{y}$ doğrultusunda meydana gelirken hasarlı durumda $\mathrm{x}$ doğrultusunda oluşmaktadır.

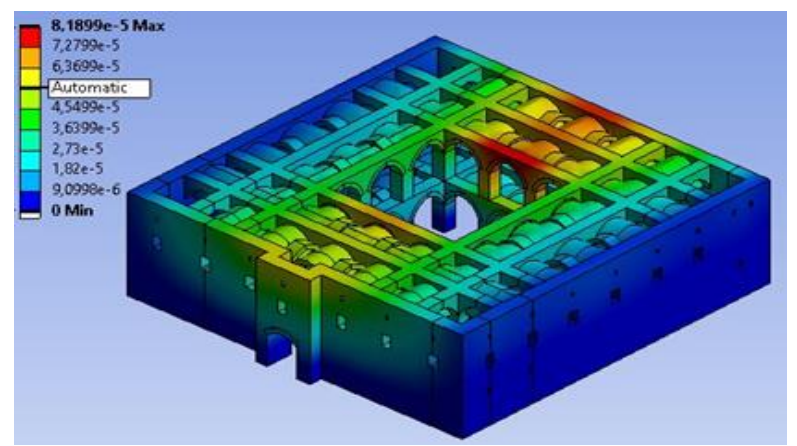

(a)

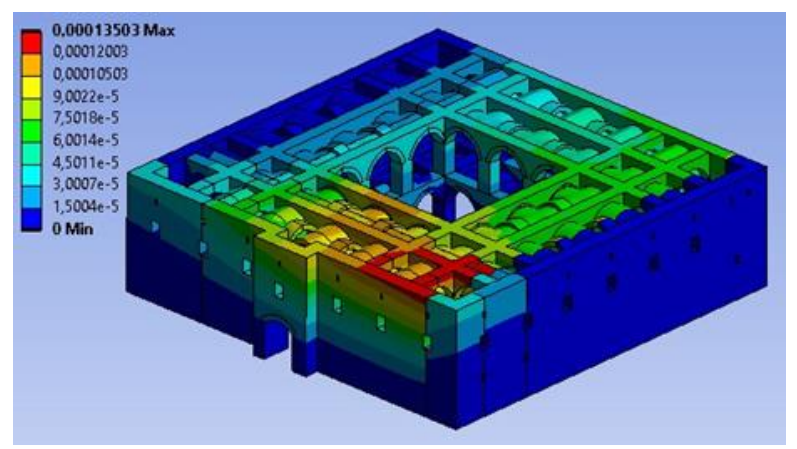

(b)

Şekil 9. (a) Hasarsız ve (b) hasarlı durum için ortalama maksimum yerdeğiştirme değerleri (m)

Şekil 10'da 1-1, 2-2 ve 3-3 kesitleri boyunca yapının hasarsız ve hasarlı durumları için elde edilen yerdeğiştirme değerleri gösterilmektedir. Şekil 10(a)'da her iki durum için yerdeğiştirmenin yükseklik boyunca arttı̆̆ı gözlenirken hasarlı durumda hasarsiz durumdakine oranla fazla olduğu anlaşılmaktadır. Şekil 10(b) ve Şekil 10(c)'de hasarlı durumda hasarsız duruma göre yerdeğiştirmeler daha fazla oluşurken çatlaklı bölgelere gelindiğinde ani sıçramaların olduğu gözlenmektedir.



(a)

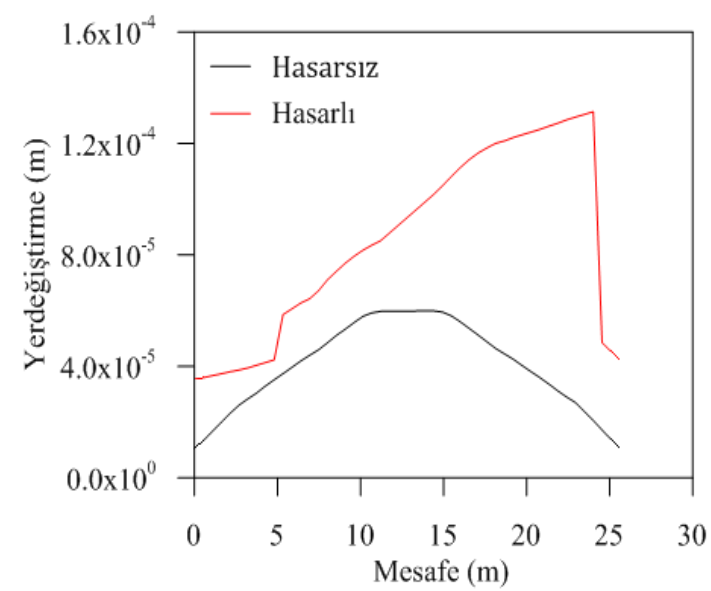

(b)

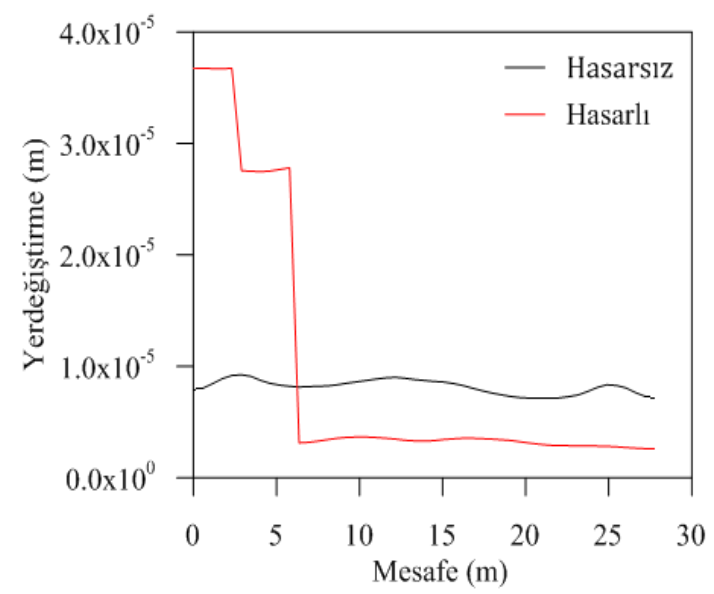

(c)

Şekil 10. (a) $1-1$, (b) $2-2$ ve (c) 3-3 kesitleri boyunca elde edilen ortalama maksimum yerdeğiştirme değerleri (m) 
Şekil 11'de 1-1, 4-4 ve 5-5 kesitleri boyunca yapının hasarsız ve hasarlı durumları için elde edilen yerdeğiştirme değerleri gösterilmektedir. Şekillerden de görüldüğü gibi hasarlı durumda meydana gelen gerilmeler hasarsiz duruma oranla daha fazladır. Ayrıca yerdeğiştirmelerde olduğu gibi hasarlı durumda çatlak bölgelerine yaklaştıkça gerilme değerlerinin arttığı ve ani sıçramaların meydana geldiği gözükmektedir.



(a)

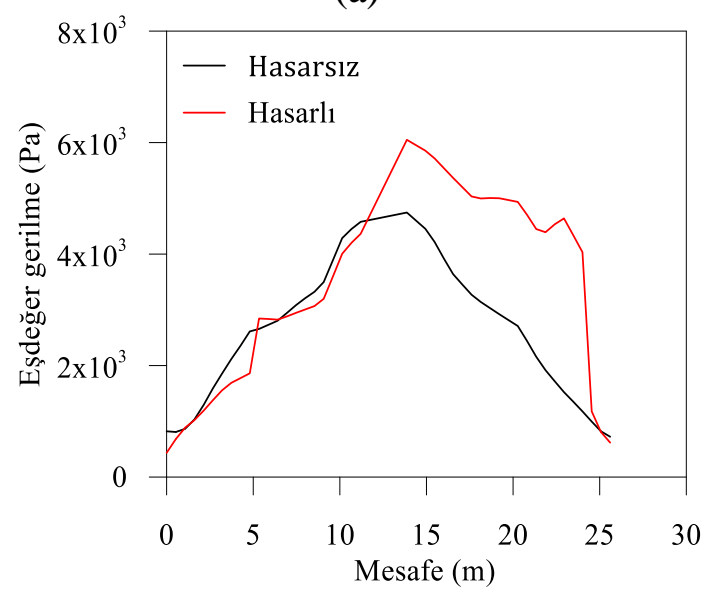

(b)

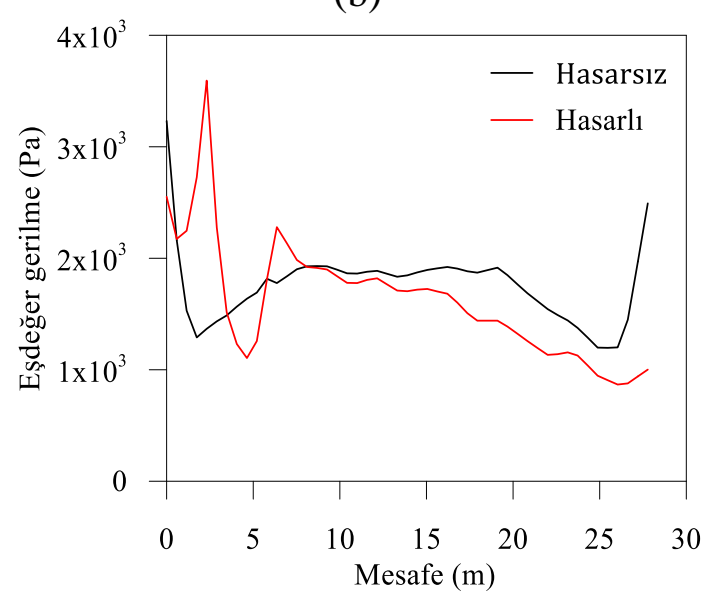

(c)

Şekil 11. (a) 1-1, (b) 4-4 ve (c) 5-5 kesitleri boyunca elde edilen ortalama maksimum eşdeğer gerilme değerleri $(\mathrm{Pa})$

\section{Sonuçlar}

Trafik kaynaklı rastgele yer hareketi etkisi altındaki tarihi yı̆̆ma yapıların dinamik davranışlarının tespiti amacıyla gerçekleştirilen bu çalışma için örnek olarak Samsun ilinde yer alan Tarihi Taşhan yapısı seçilmiştir. Yapının malzeme özelliklerinin tespiti amaciyla taş ve tuğlalardan alınan örnekler laboratuvar ortamında tahribatlı ve tahribatsız, hem de yerinde tahribatsız yöntemler uygulanmıştır. Yerinde tahribatsız yöntem olarak ultrasonik hız testi uygulanmış ve taş duvar, tuğla kemer ve taş kolonlar için belirlenen noktalardan ölçümler alınmıştır. Mevcut yapıda kullanılan taş kolon, taş duvar ve tuğla kemer için ortalama olarak malzeme özellikleri tespit edilmiştir. $\mathrm{Bu}$ malzeme özellikleri trafik etkisi altındaki yapının dinamik davranışlarının tespiti amacıyla kullanılmıştır. Analizler, yapının hasarsız (çatlaksız) ve hasarlı (çatlaklı) halleri için gerçekleştirilmiştir. Bu çalışmalar ile aşağıdaki sonuçlara ulaşı1mıştır.

- Yerinde ve laboratuvar ortamında gerçekleştirilen malzeme analizleri birbirleriyle uyumlu sonuçlar vermiştir. Yerinde ve laboratuvar ortaminda uygulanan ultrasonik test çalışmaları sonucunda elde edilen veriler uyumlu olmakla birlikte tahribatl1 olarak elde edilen malzeme özellikleri ile de yakın sonuçlar elde edilmiştir.

- Yapının kemer, kolon ve duvarlarından alınan ölçümler yapının genel malzeme özelliğini temsil edebilecek şekilde planlanmıştır. Genel itibariyle kemerlerden, kolonlardan ve duvarlardan alınan ölçümler ile ayrı ayrı birbirlerine yakın olacak değerler elde edilmiștir. $\mathrm{Bu}$ durumda hasarsız olarak belirlenen malzeme özelliklerinin yapının analizleri için kullanılacak doğrulukta olduğu söylenebilmektedir.

- Rastgele trafik etkisi altındaki yapının analiz sonuçlarından beklenildiği üzere hasarlı durumda elde edilen dinamik davranışların daha büyük olduğu görülmektedir. Ayrıca hasarlı durumdaki çatlak bölgelerine yaklaştıkça hem yerdeğiştirme hem de gerilme değerlerinde sıçramaların olduğu görülmektedir.

- Elde edilen bu analizler sonucunda trafik yükü etkilerinin yapının davranışına küçük de olsa etki ettiğini söylemek mümkündür. Özellikle yapının çatlaklı durumunda bu etkilerin arttığı gözlenmektedir. 


\section{Teşekkür}

Bu çalışma, Samsun Vakıflar Bölge Müdürlüğü tarafindan elde edilen veriler ile gerçekleştirilmiştir.

\section{Kaynaklar}

ANSYS., 2013. Workbench 2013. User's Manual, Ansys Incorporation, Ansys, Inc., Canonsburg, PA.

Başaran, H., Demir, A., Ercan, E., Nohutçu, H., Hökelekli, E. ve Kozanoğlu, C., 2016. Investigation of Seismic Safety of a Masonry Minaret Using Its Dynamic Characteristics. Earthquake and Structures, 10, 523-538.

Bongiovanni, G., Clemente, P., Rinaldis, D., ve Saitta, F., 2011. Traffic Induced Vibrations in Historical Buildings, In Proceedings of the $8^{\text {th }}$ International Conference on Structural Dynamics, EURODYN 2011, July 2011, Leuven, Belgium. pp. 812-819.

Clough, R.W. ve Penzien, J., 1993. Dynamics of Structures: Singapore, McGraw Hill, 738 p.

Crispino, M. ve D’Apuzzo, M., 2001. Measurement and Prediction of Traffic-Induced Vibrations in a Heritage Building. Journal of Sound and Vibration, 246, 319-335.

Ercan, A., 2003. Mühendislik Jeofiziği Dizisi-II: İstanbul, Birsen Yayınevi, $187 \mathrm{~s}$.

Erkal, A., 2017. Transmission of Traffic-induced Vibrations on and Around the Minaret of Little Hagia Sophia. International Journal of Architectural Heritage, 11, 349-362.

Erkal, A., 2018. Tren Geçişlerinin Küçük Ayasofya Cami Üzerinde ve Yanındaki Serbest Zemin Yüzeyinde Oluşturduğu Titreşimlerin Deneysel Olarak İncelenmesi. Uludağ University Journal of the Faculty of Engineering, 22, 361-374.

Erkal, A., Laefer, D., Fanning, P., Durukal, E., Hancilar, U. ve Kaya, Y., 2010. Investigation of the Rail-Induced Vibrations on a Masonry Historical Building. Advanced Materials Research, 133-134, 569-574.

Faella, G., Frunzio, G., Guadagnuolo, M., Donadio, A. ve Ferri, L., 2012. The Church of the Nativity in Bethlehem: Non-destructive Tests for the Structural Knowledge. Journal of Cultural Heritage, 13, e27-e41.

Freund, L.B., 1998. Dynamic Fracture Mechanics: Cambridge, Cambridge University Press, 584 p.
Gardner, G.H.F., Gardner, L.W. ve Gregory, A.R., 1974. Formation Velocity and Density-The Diagnostic Basic for Stratigraphic Traps. Geophysics, 39(6), 770-780.

Kanai, K., 1957. Semi-Empirical Formula for the Seismic Characteristics Of The Ground. Bulletin of the Earthquake Research Institute, University of Tokyo, 35, 309-324.

Kliukas, R., Jaras, A., ve Kačianauskas, R., 2008. Investigation of Traffic-Induced Vibration in Vilnius Arch-Cathedral Belfry. Transport, 23, 323-329.

Lin, Y.K., 1967. Probabilistic Theory of Structural Dynamics: New York, McGraw Hill, 366 p.

Ma, M., Markine, V., Liu, W., Yuan, Y., ve Zhang, F., 2011. Metro Train-induced Vibrations on Historic Buildings in Chengdu, China. Journal of Zhejiang University-SCIENCE A, 12, 782793.

Manolis, G.D. ve Koliopoulos, P.K., 2001. Stochastic Structural Dynamics in Earthquake Engineering: Southampton, WIT Press, 296 p.

Mesquita, E., Martini, R., Alves, A., Mota, L., Rubens, T., Antunes, P. ve Varum, H., 2018. Heterogeneity Detection of PortugueseBrazilian Masonries Through Ultrasonic Velocities Measurements. Journal of Civil Structural Health Monitoring, 8, 847-856.

Moropoulou, A., Bakolas, A., Aggelakopoulou, E., Pineli, T. ve Prassianakis, I., 2003. Estimation of Elastic Constants of Stones, used in Historic Monuments, using Ultrasonic Technique and Correlation to Their Microstructure, In The $3^{\text {rd }}$ International Conference on Non-Destructive Testing of the Hellenic Society for NDT, October 2003, Chania, Crete, Greece, pp. 242245.

Öziçer, S. ve Uyanık, O., 2017. Beton Dayanımının Yerinde P Dalga Hizından Belirlenmesi ve İzmir Örneği. SDU International Journal of Technological Sciences, 9, 1-16.

Richart, F.E., Hall, J.R. ve Woods, R.D., 1970. Vibrations of Soils and Foundations: Englewood Cliffs, New Jersey, Prentice-Hall Inc, $414 \mathrm{p}$.

Sabbağ, N. ve Uyanık, O., 2017. Prediction of Reinforced Concrete Strength by Ultrasonic Velocities. Journal of Applied Geophysics, 141, $13-23$.

Sabbağ, N. ve Uyanık, O., 2018. Determination of the Reinforced Concrete Strength by Apparent Resistivity Depending on the Curing 
Conditions. Journal of Applied Geophysics, $155,13-25$.

Tajimi, H. 1960. A Statistical Method for Determining the Maximum Response of a Building Structure During an Earthquake, In Proceedings of the $2^{\text {nd }}$ World Conference on Earthquake Engineering, July 1960, Tokyo and Kyoto, Japan. pp. 781797.

Uyanık, O., Gülay, F.G. ve Tezcan, S., 2012. Beton Dayanımının Tahribatsı Ultrasonik Yöntemle Tayini. Hazır Beton, 109, 82-85.

Uyanık, O., Kaptan, K., Gülay, F.G. ve Tezcan, S., 2011. Beton Dayanımının Tahribatsız Ultrasonik Yöntemle Tayini. Yapı Dünyası, 184, 55-58.

Uyanık, O., Sabbağ, N., Uyanık, N.A. ve Öncü, Z., 2019. Prediction of Mechanical and Physical Properties of Some Sedimentary Rocks from Ultrasonic Velocities. Bulletin of Engineering Geology and the Environment, 78, 6003-6016.
Uyanık, O., Şenli, G. ve Çatlığlu, B., 2013. Binaların Beton Kalitesinin Tahribatsız Jeofizik Yöntemlerle Belirlenmesi. SDU International Journal of Technologic Sciences, 5, 156-165.

Vasanelli, E., Calia, A., Colangiuli, D., Micelli, F. ve Aiello, M.A., 2016. Assessing the Reliability of Non-destructive and Moderately Invasive Techniques for the Evaluation of Uniaxial Compressive Strength of Stone Masonry Units. Construction and Building Materials, 124, 575581.

Yang, C.Y., 1986. Random Vibration of Structures: New York, Wiley Interscience, 295 p.

Yang, J.N. ve Agrawal, A.K., 2001. Protective Systems for High-technology Facilities Against Microvibration and Earthquake. Structural Engineering and Mechanics, 10, 561-575.

Zielińska, M. ve Rucka, M., 2018. Non-Destructive Assessment of Masonry Pillars using Ultrasonic Tomography. Materials, 11, 2543. 